\title{
УНИФИЦИРОВАННОЕ ПРАВОВОЕ ПОЛЕ ИННОВАЦИОННОГО ЭКОНОМИЧЕСКОГО РАЗВИТИЯ И НАНОТЕХНОЛОГИЙ ЕС
}

\begin{abstract}
Аннотация: Статья посвящена проблемам законодательного обеспечения инновационного экономического развития, в ичелом, и нанотехнологий, в частности, в рамках региональных интеграционных союзов, где разрабатываются общие нормы права, устанавливаюшие единообразные правила поведения для всех субъектов соответствуюшего объединения. Интенсификация прочессов гармонизации и унификации хозяйственного права ЕС характеризуется появлением качественно-новых международно-правовых норм прямого действия, обеспечиваютих эффективный единообразный переход стран-участнии ЕС от постиндустриальной экономики к инновационной. Для обеспечения планомерного и безопасного развития инновационной инфраструктуры объединенная Европа демонстрирует активную разработку программных документов, соглашений по осущчествлению финансирования нано разработок, распределению расходной части финансирования высокорисковых проектов между государством и частными инвесторами, проведению спеияиализированных исследований по регулированию объектов интеллектуальной собственности, обеспечению безопасности общественного здоровья, безопасности защчиты потребителей и работников, защчтты окружающей среды.

Ключевые слова: Юриспруденция, инновачионная экономика, нанотехнологии, региональные интеграционные союзы, общее экономико-правовое пространство, общче нормы права, рамочные программы, европейский союз, интеграционное право, инновационная экономическая деятельность
\end{abstract}

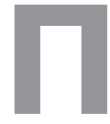
роблемы законодательного обеспечения инновационного экономического развития, в целом, и нанотехнологий, в частности, в рамках региональных интеграционных союзов, где разрабатываются общие нормы права, устанавливающие единообразные правила поведения для всех субъектов соответствующего объединения рассмотрим на примере законодательства стран-участниц ЕС.

Страны-участницы международной организации демонстрируют устойчивую современную общемировую тенденцию перехода от постиндустриальной экономики к инновационной лишь с разной степенью желаемых достижимых эффектов. ${ }^{1}$ Общепризнанного определения категории «инновационная экономика» в науке не существует. И. В. Шевченко отмечает, что инновационная экономика базируется на «интеллектуальных ресурсах, наукоемких и информационных технологиях, эффективном использовании и качественном совершенствовании

${ }^{1}$ См. подробнее: Иншаков О.B. Стратегия и тактика государственной политики развития наноиндустрии в России: Материалы к докладу на Общем собрании Отделения общественных наук РАН. 13 декабря 2010 г. Москва. - Волгоград: Изд-во ВолГУ, 2010. всех факторов производства»². И. С. Матеров определяет инновационную экономику как экономику «основанную на знаниях, инновациях, на доброжелательном восприятии новых идей, новых машин, систем и технологий, на готовности их практической реализации в различных сферах человеческой деятельности». Принципиального отличия между этими определениями нет, они схожи тем, что инновационная экономика основана на постоянном совершенствовании технологий, производстве и экспорте высокотехнологичной продукции. Развитие и внедрение новых технологий дает надежду на разрешение самых острых проблем XXI века (истощение энергоресурсов, изменение климата, безопасность продуктов питания, старение населения и др.), а также является одним из путей повышения уровня жизни населения и важным фактором экономического развития любого государства. Академик В.И. Жуков в своей работе «The World Crisis:

\footnotetext{
${ }^{2}$ Шевченко, И.В., Александрова, Е.Н. Инновационная экономика: вопросы теории и основные тенденции развития // Финансы и кредит. - 2005. - № 14. - С. 7-16.

${ }^{3}$ Матеров, И.С. Факторы развития «новой экономики» в России
} // Экономист. - 2003. - №2. - С. 3-11. 


\section{Право и политика 7 (163) • 2013}

Economics and Sociology of Global Processes» обстоятельно проанализировав совокупность причин современного экономического кризиса, помимо финансовой, в перечне главных причин выделяет смену технологического уклада и переход к так называемому шестому его этапу. «В настоящее время, - отмечает ученый, - почти все отрасли производства достигли высшей точки своего развития. Теперь без технологической революции в энергетике, материаловедении, генетике, медицине, информатике и других областях прогресс невозможен». ${ }^{4}$

В этой связи создание комфортных условий для научно-исследовательской деятельности, обеспечение кооперации научных учреждений и финансирования инновационных проектов является важной задачей для государства. Правительство Российской Федерации не остается равнодушным к решению объективно обусловленным мировым экономическим развитием задач и в последнее время уделяет все большее внимание развитию науки и новых технологий 5 .

Процесс трансформации правового обеспечения создания современной инновационной инфраструктуры в рамках региональных интеграционных объединений имеет свою специфику, отражающуюся, в первую очередь, в интенсификации развития государственно-частного партнерства, как элемента замкнутого инновационного цикла, идущего от научной идеи к конкретному промышленному продукту, который должен быть востребован рынком и «встроен» в существующие технологические цепочки.

Анализ правовых документов, разработанных таким региональным интеграционным образованием как Европейский Союз (далее - EC), позволяет выявить основные сферы развития современной инновационной инфраструктуры, развития инновационной деятельности и государственно-частного партнерства. Такими приоритетными направлениями, с точки зрения, как эффективного экономического развития региона, так и регионального

\footnotetext{
${ }^{4}$ В.И. Жуков The World Crisis: Economics and Sociology of Global Processes. - M.: - Publishing House «Soyuz», 2009. Данная монография посвящена мировому кризису, рассматриваемому автором как единение экономических и социологических аспектов, как глобальный процесс. В работе раскрывается природа кризиса; анализируется антикризисный финансовый, интеллектуальный, технологический и кадровый потенциал ведущих стран мира в сопоставлении с возможностями России. В данной работе большое значение уделяется выявлению резервных возможностей России и освещению ее конкурентных преимуществ. (Здесь и далее прим. автора)

${ }^{5}$ См. подробнее: Ежемесячный правовой журнал «Законы России: опыт, анализ, практика». - № 9 (сентябрь) 2011. Научный консультант главной темы «Наноиндустрия и право»- д.ю.н., профессор А.О. Иншакова. Например: Иншакова, А.O. Вклад частного права в развитие отечественной наноиндустрии: унификационные тенденции / А.О. Иншакова // Законы России: опыт, анализ, практика. - Москва. - № 9 (сентябрь). - С. 37-44.
}

законотворчества, следует считать создание общего экономико-правового пространства науки и образования ${ }^{6}$ и рынка высокотехнологичной продукции. ${ }^{7}$

Для обеспечения планомерного и безопасного развития инновационной инфраструктуры необходима разработка программных документов, соглашений по осуществлению финансирования нано разработок, распределению расходной части финансирования высокорисковых проектов между государством и частными инвесторами, проведения специализированных исследований по регулированию объектов интеллектуальной собственности, обеспечению безопасности общественного здоровья, безопасности защиты потребителей и работников, защиты окружающей среды.

Как регулирующие органы, так и экспертное научное сообщество признают, что риски, связанные с применением нанотехнологий на сегодняшний день мало изучены. ${ }^{8}$

В соответствии с Постановлением Правительства РФ от 23.04.2010 № 282 «О национальной нанотехнологической сети» нанотехнологии - технологии, направленные на создание и практическое использование нанообъектов и наносистем с заданными свойствами и характеристиками. В целом же наноиндустрия представляет собой межотраслевой комплекс организаций, а также междисциплинарный комплекс организаций (комплекс организаций, осуществляющих деятельность в рамках различных научных дисциплин на основе единого подхода к рассмотрению материи на атомно-молекулярном уровне), обеспечивающих и осуществляющих целенаправленную деятельность по разработке и коммерциализации нанотехнологий. ${ }^{9}$

В современном юридическом понимании, нашедшем отражение в научной литературе, нанотехнология - это целенаправленная человеческая деятельность по произ-

\footnotetext{
${ }^{6}$ Иншакова А.О. Региональная унификация правового регулирования образования в аспекте подготовки и аттестации научных кадров высшей квалификации // Вестник Финансовой академии при правительстве РФ. - Москва. - 2010. - № 4. - С. 26 - 32; Иншакова А.О. Общие закономерности и перспективные тенденции развития глобального уровня правового регулирования образования // Вестник Волгоградского государственного университета. - Серия 5. Юриспруденция. - Волгоград. - 2010. - № 1 (12). - С. 99 - 106; Иншакова А.О. По итогам системного исследования зарубежной нормативно-правовой базы регулирования аттестации научных кадров // Образование и право. Научно-правовойжурнал. - Москва. - 2010. - № 8 (12) август. - С. 24 - 40.

${ }^{7}$ Акопов Э. Евросоюз: техническое регулирование в сфере нанотехнологий// Научно-технический журнал «Наноиндустрия».2010.- № 3. - C. 18-20.

${ }^{8}$ См., например: Иншакова, А.О., Шишенко М.С. Правовое регулирование минимизации инвестиционных рисков в сфере наноиндустрии // Вестник Волгоградского государственного университета. - Серия 5. - Юриспруденция. - Волгоград. - 2011. - № 2 (15) - C. 82-90.

${ }^{9}$ Собрание законодательства РФ. - 2010. - № 18. - Ст. 2250.
} 
водству и использованию (включая отображение, измерение, моделирование и управление материей) материалов с преднамеренно внедренными особенностями, вплотную к атомному или молекулярному масштабу, имеющих размер от 1 до 100 нм. $^{10}$

Появление качественно-новых международноправовых норм прямого действия, обеспечивающих эффективный единообразный переход стран-участниц ЕС от постиндустриальной экономики к инновационной, в том числе и в отношении хозяйствующих субъектов регионального объединения как непосредственных акторов микроуровня глобальной экономической системы, действующих в статусе ранее неизвестных организационно-правовых формах ведения предпринимательской деятельности логично, изучать на примере гармонизации и унификации права ЕС, достигшего наивысшей степени региональной правовой интеграции. ${ }^{11}$ Кроме того, в российском частноправовом регулировании общие традиции европейского континентального права остаются доминирующими.

Изучение опыта Европейского союза - главного стратегического внешнеэкономического партнера России, в этом направлении может оказаться весьма ценным при планировании аналогичной отечественной политики. Исследование унифицированных норм ЕС в целях совершенствования российского правового регулирования сферы наноиндустрии становится тем более актуальным, чем большую поддержку получает концепция формирования и развития «единого европейского экономического пространства».

В данном контексте, в первую очередь, исследовательского внимания заслуживает опыт ЕС в разработке программных документов, создающих основу развития наноиндустриализации. Еще в 2004 году Комиссией ЕС был принят подход «О Европейской стратегии в сфере нанотехнологий». ${ }^{12}$ В 2005 году Комиссия ЕС приняла План действий в области науки и нанотехнологий. ${ }^{13}$ В 2006

10 Зульфугарзаде Т.Э., Хатаева М.А. Основы правового регулирования нанотехнологий в Российской Федерации // Адвокат. - 2009. - № 5. - С. 93-113.

${ }^{11}$ Иншакова, А.О. Новые формы хозяйствования как слагаемые успеха интеграции РФ в единое экономическое пространство с ЕС // Право и государство: теория и практика. - Москва. - 2010. - № 10 (70).- С. 98-104; Иншакова А.О. Европейские минимальные правовые стандарты в российском антимонопольном регулировании (часть 2) // Цивилист. - Москва. - 2010. - № 3 (июль-сентябрь). - С. 90 -97.

${ }^{12}$ Communication from the Commission «Towards a European strategy for nanotechnology», 12.5.2004 COM (2004) 338 final. Интернет-сайт представительства Комиссии ЕС в России. URL: http://www. delrus. cec. eu. int/ (дата обращения: 15.03.2013).

${ }^{13}$ Communication from the Commission «Nanosciences and nanotechnologies: An Action Plan for Europe 2005-2009, 07/06/2005 COM (2005) 243 final. Интернет-сайт представительства Комиссии году Комиссия ЕС приняла Инновационную стратегию Европейского Союза. ${ }^{14}$ Эти правовые акты ЕС направлены на регулирование вопросов финансирования наноразработок, развития государственно-частного партнерства, разработку кадровой и образовательной политик, связанных с требованиями инновационной экономики.

Вопросам правового обеспечения процесса развития наноиндустрии также уделяется значительное внимание при разработке многолетних рамочных программ ЕС основного финансового инструмента ЕС для поддержки и развития научных исследований и технологических разработок, предусмотренного главой XIX договора о функционировании ${ }^{15}$.

Изучение и анализ упомянутых программ как правовой основы развития и финансирования инновационной экономики регионального интеграционного объединения, важно для России, принимающей участие в седьмой рамочной программе в качестве одной из стран, входящих в список «International Cooperation Partner Countries» $(\mathrm{ICPC})^{16}$, наряду со странами участие в которой принимают международные организации.

С 1984 года Европейский союз путем принятия рамочных программ создавал условия для развития науки и поощрял исследовательскую деятельность. Это позволило выработать новый подход, основанный на кооперации, быстром и свободном обмене информацией и результатами исследований. Между тем, к 2000 году научно-исследовательский сектор в ЕС все еще был слишком фрагментирован, Европа отставала по доле ВВП в инновационной сфере от своих ближайших конкурентов (США и Япония). Для преодоления этих проблем Европейская комиссия в январе 2000 года выступила с предложением о создании единой Европейской исследовательской зоны (далее-ERA), которое было принято в марте того же года на саммите EC в Лиссабоне ${ }^{17}$.

EC в России. URL: www.delrus.ec.europa.eu/ (дата обращения: 15.03.2013).

${ }^{14}$ Communication from the Commission «Putting knowledge into practice: A broad-based innovation strategy for the EU» 13.09.2006 COM (2006) 502 final. Интернет-сайт представительства Комиссии EC в России. URL: www.delrus.ec.europa.eu/ (дата обращения: 15.03.2013).

${ }^{15}$ Consolidated version of the Treaty on the Functioning of the European Union URL: http://eur-lex.europa.eu/LexUriServ/LexUriServ.do?uri= OJ:C:2010:083:0047:0200:EN:PDF (дата обращения: 15.03.2013).

${ }^{16}$ См. подробнее: Иншакова, Е.И. Международное сотрудничество России в сфере наноиндустрии: направления и формы // Законы России: опыт, анализ, практика. 2011. № 9 С. 23-28.

${ }^{17}$ Communication from the Commission to the Council, the European Parliament, the Economic and Social Committee and the Committee of the Regions - Towards a European research area URL: http://eur-lex.europa.eu/LexUriServ/LexUriServ.do?uri=CELEX:52000DC0006:EN:NOT (дата обращения: 15.03.2013). 


\section{Право и политика $7(163) \cdot 2013$}

Концепция ERA предлагала установить границы зоны, свободной для научных исследований, увеличить количество рабочих мест и тем самым повысить конкурентоспособность Европы. Она сочетает в себе три идеи:

1. создание «внутреннего рынка» инноваций, основанного на свободном обмене знаниями, технологиями и научными кадрами, кооперации, стимулировании конкуренции и оптимальном распределении ресурсов;

2. реструктуризация европейских исследовательских организаций с целью улучшения координации национальных программ в области инноваций;

3. развитие общеевропейской политики в отношении инноваций, в том числе осуществление финансирования исследовательских проектов, учитывая все нюансы как национальных, так и общеевропейских стратегий развития.

Для реализации этих идей концепция ERA предусматривала следующие меры:

Оптимизация материальных ресурсов и возможностей на общеевропейском уровне;

1. Согласованное использование государственных инструментов и ресурсов. В рамках предложенной идеи кооперации и открытости в Европе были учреждены научно-исследовательские организации, имеющие межгосударственный характер. К таким организациям относятся: Европейское научное общество (European Science Foundation, ESF), Европейское космическое агентство (European Space Agency, ESA), Европейское сотрудничество в области научно-технических исследований (European Cooperation in the field of Scientificand Technical Research, COST);

2. Привлечение инвестиций из частного сектора. В рамках этой задачи предлагалось поощрение венчурных инвестиций, создание предприятий, а также разработка эффективных средств защиты интеллектуальной собственности. Краеугольным камнем в решении данной задачи был и остается вопрос защиты интеллектуальной собственности.

3. Создание единой системы научно-технического консультирования для подготовки и осуществления политики ЕС. Европейская система исследований должна быть организована с учетом потребностей, возникающих на различных этапах реализации государственной политики.

4. Решение проблемы нехватки кадров и повышение мобильности европейских исследователей;

5. Повышение привлекательности ЕС для исследователей и инвестиций;

6. Выработка общей позиции в отношении этических проблем науки и технологий. В рамках данной задачи необходимо было наладить диалог между исследователями и другими секторами общества (гражданами, экспертами, руководителями предприятий, политиками), укрепить связи между национальными и общеевропейскими комитетами по этике и выработать общий подход, общее видение этических вопросов, связанных с наукой и техникой.

Основными финансовыми инструментами для развития ERA стали последовательно вначале 6 Рамочная программа $\mathrm{EC}^{18}$, принятая на период с 2002 по 2006 гг., а затем 7 Рамочная программа $\mathrm{EC}^{19}$, принятая на период с 2007 по 2013 гг.

Главной целью шестой рамочной программы было создание единого Европейского исследовательского пространства путем содействия большей интеграции и координации в ранее сильно фрагментированном научноисследовательском секторе Европы.

Также программа предусматривает введение двух новых инструментов: сети передовых технологий и комплексных (объединенных) проектов.

Целью сетей передовых технологий являлась постепенная интеграция деятельности партнеров. Комплексные проекты же представляли собой масштабные исследовательские проекты, сочетающие в себе частное и государственное финансирование и направленные на решение четко установленных научно-технических задач. Они составили основу исследований в Европе.

Кроме того, шестая рамочная программа регулировала деятельность Объединенного исследовательского центра (JRC).

Любое физическое или юридическое лицо могло подать заявку на участие в программе и получить поддержку. Другими словами, университеты, международные организации, исследовательские институты, малые, средние предприятия и крупные компании могли принять участие в программе.

\footnotetext{
${ }^{18}$ Decision No $1513 / 2002 /$ EC of the European Parliament and of the Council of 27 June 2002 concerning the sixth framework programme of the European Community for research, technological development and demonstration activities, contributing to the creation of the European Research Area and to innovation (2002 to 2006) URL: http://eur-lex.europa.eu/LexUriServ/LexUriServ. do?uri=CELEX:52000DC0006:EN:NOT (дата обращения: 15.03.2013).

${ }^{19}$ Decision No 1982/2006/EC of the European Parliament and of the Council of 18 December 2006 concerning the Seventh Framework Programme of the European Community for research, technological development and demonstration activities (2007-2013) URL: http://eur-lex.europa.eu/LexUriServ/LexUriServ.do?uri=CELEX:32006D1982:EN:NOT (дата обращения: 15.03.2013), 2006/969/EC: Council Decision of 18 December 2006 concerning the Seventh Framework Programme of the European Atomic Energy Community (Euratom) or nuclear research and training activities (2007 to 2011) URL: http://eur-lex.europa.eu/LexUriServ/ LexUriServ.do?uri=CELEX:32006D0969:EN:NOT (дата обращения: 15.03.2013).
} 
Важным моментом стало то, что исследователи из стран-кандидатов могли получать поддержку в рамках программы на равных условиях с исследователями из стран-участниц. До принятия шестой рамочной программы это было возможно только в том случае, если они сотрудничали с исследователями из ЕС.

Следующим шагом на пути создания единого ERA стала седьмая рамочная программа по исследованиям, технологическому развитию и демонстрационной деятельности (2007-2013), принятая в 2006 году и действующая в настоящее время. Данная программа была разработана ЕС совместно с РФ. Основной целью этой программы является поддержка и развитие науки и исследований в едином пространстве стран-участниц ЕС, а также повышение конкурентоспособности европейских исследований, образовательных и инновационных сфер. Эта программа также является одним из важнейших элементов реализации Лиссабонского договора по развитию и конкурентоспособности ${ }^{20}$.

7-я Рамочная программа адаптирована к потребностям ЕС в плане экономического роста и занятости. После консультаций с общественностью, были определены четыре основных направления, которым соответствуют четыре специальные программы.

1. Сотрудничество. Целью данной программы является содействие сотрудничеству между предприятиями, исследовательскими центрами и органами государственной власти в ЕС, а также поддержание международного сотрудничества. Данная программа охватывает десять «тематических» областей, соответствующих основным областям знаний и технологий, в которых необходима поддержка транснационального сотрудничества в целях решения социальных, экономических, экологических и промышленных задач, в том числе и нанонауки, нанотехнологии, материалы и новые производственные технологии.

2. Идеи (инновации). Программа предназначена для поощрения инновационных исследований в Европе, то есть исследований, направленных на открытие новых знаний, которые в корне меняют наше представление о мире и наш образ жизни.

3. Люди. В программу заложены значительные финансовые ресурсы для улучшения карьерных перспектив ученых в Европе и привлечения большего количества высококвалифицированных молодых исследователей.

4. Мощънсти. Программа предназначена дать исследователям мощный инструмент, который позволит им повысить качество и конкурентоспособность европейских исследований.

${ }^{20}$ Иншакова, А.О. Задачи межгосударственного цивильного права в сфере наноиндустрии [Текст] : препринт / О.А. Иншакова; Гос. образоват. учреждение высш. проф. образования «Волгогр. гос. ун-т». - Волгоград: Издательство ВолГУ, 2011. - 32 с.
Кроме того, 7-я Рамочная программа будет финансировать на прямую деятельность Объединенного исследовательского центра (JRC) и действия, Евратома, охватываемые Рамочной программой. Это исследования в области термоядерной энергетики, в области ядерного деления и радиационной защиты.

Как и в случае с Шестой рамочной программой, некоторые области исследований не будут получать финансирование Сообщества:

- $\quad$ клонирование человека;

- $\quad$ исследования с целью изменения человеческого генофонда (в том случае, когда изменения носят наследственный характер);

- $\quad$ исследования с целью создания человеческих эмбрионов только для исследовательских целей или для получения стволовых клеток.

Сохраняя лучшие черты предыдущих программ, 7-я Рамочная программа вводит новые меры, направленные на повышение согласованности и эффективности научно-исследовательской политики ЕС. Основными нововведениями в рамках программы являются:

- $\quad$ упрощение процедуры участия в программе;

- создание Европейского исследовательского совета в рамках программы Идеи (инновации) для поддержки инновационных исследований;

- $\quad$ улучшение сотрудничества с промышленностью через совместные технологические инициативы, использующие как частные инвестиции, так и государственное финансирование;

- поддержка европейской политики в области построения исследовательской инфраструктуры;

- создание механизма распределения финансовых рисков, чтобы облегчить участникам получение кредита в Европейском инвестиционном банке.

Принять участие в седьмой рамочной программе могут $^{21}$ :

- Страны-участницы ЕС.

- Ассоциированные страны - имеющие соглашение с Европейским союзом о сотрудничестве в сфере науки и технологий и вносящие определенный финансовый вклад в бюджет рамочных программ (Швейцария, Израиль, Норвегия, Исландия, Лихтенштейн, Турция, Хорватия, Македония, Албания, Босния и Герцеговина, Молдова, Черногория, Сербия).

- Страны-кандидаты.

- Третьи страны - не участницы и не ассоциированные страны. Их участие должно быть оправдано вкладом в достижение целей рамочных программ.

\footnotetext{
${ }^{21}$ Community research and development information service (CORDIS) URL: http://cordis.europa.eu/fp7/who_en.html\#countries (дата обращения: 15.03.2013).
} 
DOI: $10.7256 / 1811-9018.2013 .7 .7847$

При цитировании этой статьи сноска на doi обязательна

\section{Право и политика 7 (163) 2013}

Седьмая рамочная программа заканчивается в 2013 году. На смену ей Европейский союз готовит новую политику в области исследований и инноваций как часть стратегии «Европа 2020»²2. Этот новый подход направлен, в частности, на поддержку инноваций в тех областях, которые представляют собой проблемы для европейского общества, такие как изменение климата, энергетическая эффективность, безопасность пищевых продуктов, здоровье и старение населения. Одной из целей также является увеличение доли инвестиций в области исследований и инноваций до $3 \%$ ВВП ЕС.

Проведенное исследование регионального уровня регулирования ЕС в сфере нанотехнологий позволяет сделать некоторые выводы относительно влияния последней на процесс трансформации источников права, выработки новых видов правовых документов и документов saft law, ранее мало известных или неизвестных вовсе. Такие документы мягкого права как: технические регламенты, рамочные программы, концепции, системы и решения составляют на сегодняшний день значительный блок в массиве соответствующего правового обеспечения. И наряду с негативными эффектами современной тенденции динамичного процесса трансформации источников частного права в сфере инновационной экономики в целом и нанотехнологий, в частности, их неспособности ввести субъектов данной сферы экономической деятельности в жесткие рамки существующего мирового правопорядка, следует отметить и их позитивные эффекты. Во-первых, гибкость регулирования, предполагающую свободу выбора методов и средств на усмотрение национального законодателя, а, во-вторых, способность оперативно подменять межгосударственное нормативно-правовое регулирование, требующее больших временных затрат для достижения согласования волеизъявления странучастниц. Последнее их качество призвано способствовать стремительному развитию объективных интеграционных процессов в области наноиндустриализации, особенно, в рамках единого экономико-правового пространства региональных межгосударственных образований.

\section{Библиография:}

1. 2006/969/EC: Council Decision of 18 December 2006 concerning the Seventh Framework Programme of the European Atomic Energy Community (Euratom)

\footnotetext{
${ }^{22}$ Communication from the Commission to the European Parliament, the Council, the European Economic and Social Committee and the Committee of the Regions Europe 2020 flagship initiative Innovation Union sec(2010) 1161 URL: http://eur-lex.europa.eu/LexUriServ/ LexUriServ.do?uri=CELEX:52010DC0546:EN:NOT (дата обращения: 15.03.2013).
}

or nuclear research and training activities (2007 to 2011) URL: http://eur-lex.europa.eu/LexUriServ/ LexUriServ.do?uri=CELEX:32006D0969:EN:NOT (дата обращения: 15.03.2013).

2. Communication from the Commission «Nanosciences and nanotechnologies: An Action Plan for Europe 20052009, 07/06/2005 COM (2005) 243 final. Интернет-сайт представительства Комиссии EC в России. URL: www.delrus.ec.europa.eu/ (дата обращения: 15.03.2013).

3. Communication from the Commission «Putting knowledge into practice: A broad-based innovation strategy for the EU» 13.09.2006 COM (2006) 502 final. Интернетсайт представительства Комиссии ЕС в России. URL: www.delrus.ec.europa.eu/ (дата обращения: 15.03.2013).

4. Communication from the Commission «Towards a European strategy for nanotechnology», 12.5.2004 COM (2004) 338 final. Интернет-сайт представительства Комиссии ЕС в России. URL: http://www. delrus. cec. eu. int/ (дата обращения: 15.03.2013).

5. Communication from the Commission to the Council, the European Parliament, the Economic and Social Committee and the Committee of the Regions - Towards a European research area URL: http://eur-lex.europa.eu/LexUriServ/ LexUriServ.do?uri=CELEX:52000DC0006:EN:NOT (дата обращения: 15.03.2013).

6. Communication from the Commission to the European Parliament, the Council, the European Economic and Social Committee and the Committee of the Regions Europe 2020 flagship initiative Innovation Union sec(2010) 1161 URL: http://eur-lex.europa.eu/LexUriServ/ LexUriServ.do?uri=CELEX:52010DC0546:EN:NOT (дата обращения: 15.03.2013).

7. Community research and development information service (CORDIS) URL: http://cordis.europa.eu/fp7/ who_en.html\#countries (дата обращения: 15.03.2013).

8. Consolidated version of the Treaty on the Functioning of the European Union URL: http://eur-lex.europa.eu/ LexUriServ/LexUriServ.do?uri=OJ:C:2010:083:0047:02 00:EN:PDF (дата обращения: 15.03.2013).

9. Decision No $1513 / 2002 /$ EC of the European Parliament and of the Council of 27 June 2002 concerning the sixth framework programme of the European Community for research, technological development and demonstration activities, contributing to the creation of the European Research Area and to innovation (2002 to 2006) URL: http://eur-lex.europa.eu/LexUriServ/ LexUriServ.do?uri=CELEX:52000DC0006:EN:NOT (дата обращения: 15.03.2013)..

10. Decision No 1982/2006/EC of the European Parliament and of the Council of 18 December 2006 concerning the Seventh Framework Programme of the European Community for research, technological development and demonstration activities (2007-2013) URL: 
http://eur-lex.europa.eu/LexUriServ/LexUriServ. do?uri=CELEX:32006D1982:EN:NOT (дата обращения: 15.03.2013).

11. Акопов Э. Евросоюз: техническое регулирование в сфере нанотехнологий// Научно-технический журнал «Наноиндустрия»,- 2010.- № 3. - С. 18-20.

12. В.И. Жуков The World Crisis: Economics and Sociology of Global Processes. - M.: - Publishing House «Soyuz», 2009.

13. Зульфугарзаде Т.Э., Хатаева М.А. Основы правового регулирования нанотехнологий в Российской Федерации // Адвокат. - 2009. - № 5. - С. 93-113.

14. Иншаков О.В. Стратегия и тактика государственной политики развития наноиндустрии в России: Материалы к докладу на Общем собрании Отделения общественных наук РАН. 13 декабря 2010 г. Москва. - Волгоград: Изд-во ВолГУ, 2010.

15. Иншакова А.О. Общие закономерности и перспективные тенденции развития глобального уровня правового регулирования образования // Вестник Волгоградского государственного университета. Серия 5. - Юриспруденция. - Волгоград. - 2010. - № 1 (12). - C. $99-106$

16. Иншакова А.О. По итогам системного исследования зарубежной нормативно-правовой базы регулирования аттестации научных кадров // Образование и право. Научно-правовойжурнал. - Москва. - 2010. - № 8 (12) август. - С. 24 - 40.

17. Иншакова А.О. Региональная унификация правового регулирования образования в аспекте подготовки и аттестации научных кадров высшей квалификации // Вестник Финансовой академии при правительстве РФ. - Москва. - 2010. - № 4. - С. 26 - 32.

18. Иншакова, А.О. Задачи межгосударственного цивильного права в сфере наноиндустрии [Текст] : препринт / О.А. Иншакова; Гос. образоват. учреждение высш. проф. образования «Волгогр. гос. ун-т». - Волгоград: Издательство ВолГУ, 2011. - 32 с.

19. Иншакова, А.О. Новые формы хозяйствования как слагаемые успеха интеграции РФ в единое экономическое пространство с ЕС // Право и государство: теория и практика. - Москва. 2010. - № 10 (70). - С. 98-104; Иншакова А.О. Европейские минимальные правовые стандарты в российском антимонопольном регулировании (часть 2) // Цивилист. - Москва. - 2010. - № 3 (июль-сентябрь). - С. 90 -97.

20. Иншакова, А.О., Шишенко М.С. Правовое регулирование минимизации инвестиционных рисков в сфере наноиндустрии // Вестник Волгоградского государственного университета. - Серия 5. Юриспруденция. - Волгоград. - 2011. - № 2 (15) - C. 82-90.
21. Иншакова, Е.И. Международное сотрудничество России в сфере наноиндустрии: направления и формы // Законы России: опыт, анализ, практика. 2011. № 9 C. 23-28.

22. Матеров, И.С. Факторы развития «новой экономики» в России // Экономист. - 2003. - №2. - С. 3-11.

23. Шевченко, И.В., Александрова, Е.Н. Инновационная экономика: вопросы теории и основные тенденции развития // Финансы и кредит. - 2005. - № 14. - С. 7-16.

\section{References (transliteration):}

1. Akopov E. Evrosoyuz: tehnicheskoe regulirovanie v sfere nanotehnologiy// Nauchno-tehnicheskiy zhurnal «Nanoindustriya».- 2010.- № 3. - S. 18-20.

2. V.I. Zhukov The World Crisis: Economics and Sociology of Global Processes. - M.: - Publishing House «Soyuz», 2009.

3. Zul'fugarzade T.E., Hataeva M.A. Osnovy pravovogo regulirovaniya nanotehnologiy v Rossiyskoy Federacii // Advokat. - 2009. - № 5. - C. 93-113.

4. Inshakov O.V. Strategiya i taktika gosudarstvennoy politiki razvitiya nanoindustrii v Rossii: Materialy k dokladu na Obschem sobranii Otdeleniya obschestvennyh nauk RAN. 13 dekabrya 2010 g. Moskva. - Volgograd: Izd-vo VolGU, 2010.

5. Inshakova A.O. Obschie zakonomernosti i perspektivnye tendencii razvitiya global'nogo urovnya pravovogo regulirovaniya obrazovaniya // Vestnik Volgogradskogo gosudarstvennogo universiteta. Seriya 5. - Yurisprudenciya. - Volgograd. - 2010. № 1 (12). - S. $99-106$

6. Inshakova A.O. Po itogam sistemnogo issledovaniya zarubezhnoy normativno-pravovoy bazy regulirovaniya attestacii nauchnyh kadrov // Obrazovanie i pravo. Nauchno-pravovoyzhurnal. - Moskva. - 2010. - № 8 (12) avgust. - S. $24-40$.

7. Inshakova A.O. Regional'naya unifikaciya pravovogo regulirovaniya obrazovaniya $\mathrm{v}$ aspekte podgotovki i attestacii nauchnyh kadrov vysshey kvalifikacii // Vestnik Finansovoy akademii pri pravitel'stve RF. - Moskva. 2010. - № 4. - S. 26 - 32 .

8. Inshakova, A.O. Zadachi mezhgosudarstvennogo civil'nogo prava $\mathrm{v}$ sfere nanoindustrii [Tekst] : preprint / O.A. Inshakova; Gos. obrazovat. uchrezhdenie vyssh. prof. obrazovaniya «Volgogr. gos. un-t». - Volgograd: Izdatel'stvo VolGU, 2011. - $32 \mathrm{~s}$.

9. Inshakova, A.O. Novye formy hozyaystvovaniya kak slagaemye uspeha integracii RF v edinoe ekonomicheskoe prostranstvo s ES // Pravo i gosudarstvo: teoriya i praktika. - Moskva. - 2010. - № 10 (70). - S. 98-104; Inshakova A.O. Evropeyskie minimal'nye pravovye 
DOI: $10.7256 / 1811-9018.2013 .7 .7847$

При цитировании этой статьи сноска на dоі обязательна

\section{Право и политика 7 (163) 2013}

standarty $\mathrm{v}$ rossiyskom antimonopol'nom regulirovanii (chast' 2) // Civilist. - Moskva. - 2010. - № 3 (iyul'sentyabr'). - S. 90 -97.

10. Inshakova, A.O., Shishenko M.S. Pravovoe regulirovanie minimizacii investicionnyh riskov $\mathrm{v}$ sfere nanoindustrii // Vestnik Volgogradskogo gosudarstvennogo universiteta. - Seriya 5. - Yurisprudenciya. - Volgograd. - 2011. - № 2 (15) - S. 82-90.
11. Inshakova, E.I. Mezhdunarodnoe sotrudnichestvo Rossii v sfere nanoindustrii: napravleniya i formy // Zakony Rossii: opyt, analiz, praktika. 2011. № 9 S. 23-28.

12. Materov, I.S. Faktory razvitiya «novoy ekonomiki»v Rossii // Ekonomist. - 2003. - №2. - S. 3-11.

13. Shevchenko, I.V., Aleksandrova, E.N. Innovacionnaya ekonomika: voprosy teorii i osnovnye tendencii razvitiya // Finansy i kredit. - 2005. - № 14. - S. 7-16. 